\title{
Pharmaceutical development of tablets containing a spray-dried optimized extract from Lippia origanoides H. B. K.: influence of excipients and toxicological assessment
}

\author{
Angélica Gomes Coelho ${ }^{1 *}$, José de Sousa Lima Neto ${ }^{2}$, Arkellau Kenned Silva Moura ${ }^{1}$, Ilmara Cecilia \\ Pinheiro da Silva Morais ${ }^{3}$, Francisco Valmor Macedo Cunha ${ }^{3}$, Bernardo Melo-Neto ${ }^{4}$, Maria das \\ Graças Freire de Medeiros $^{2}$, Eilika Andreia Feitosa Vasconcelos ${ }^{2}$, Daniel Dias Rufino Arcanjo ${ }^{3}$, \\ Lívio Cesar Cunha Nunes², Antônia Maria das Graças Lopes Citó ${ }^{1}$
}

\author{
${ }^{1}$ Laboratório de Geoquímica Orgânica, Universidade Federal do Piauí, Teresina, Piauí, Brasil, ${ }^{2}$ Curso de Farmácia, \\ Universidade Federal do Piauí, Teresina, Piaui, Brasil, ${ }^{3}$ Núcleo de Pesquisas em Plantas Medicinais, Universidade Federal do \\ Piauí, Teresina, Piauí, Brasil, ${ }^{4}$ Curso de Farmácia, Faculdade Santo Agostinho, Teresina, Piauí, Brasil
}

\begin{abstract}
Lippia origanoides is a honey shrub which has showed hypotensive potential assessed by in vivo studies. The aim of this work is the development of a pharmaceutical formulation composed by an optimized extract obtained from aerial parts of $L$. origanoides. The quantification of the naringenin marker in the dry extract and tablets developed was performed, as well as the assessment of the oral acute toxicity in rats. The hydroalcoholic extract of $L$. origanoides was spray-dried with the addition of colloidal silicon dioxide (Lo-HAE/CSD), and then applied in the preparation of eight different lots of tablets. The influence of the diluent (cellulose or babassu mesocarp), the presence of binder, and the percentage of lubricant, as well as organoleptic and physicochemical characteristics were screened. For the quantification of the marker content both in Lo-HAE/CSD and in the tablets, an analytical curve of the naringenin standard was fitted, and the samples were then analyzed in UFLC. The toxicological assessment was performed in female Wistar rats according to the Acute Toxic Class Method from OECD. The developed tablets produced meet acceptable macroscopic characteristics, and the presence of babassu as diluent provided improved physicochemical properties. The best content of Lo-HAE/CSD in the tablet (100.27\%) was identified for the lot containing babassu, composed by $1.0 \%$ magnesium stearate, without PVP binder in its formulation. Moreover, Lo-HAE/CSD showed no signs of toxicity. Therefore, the babassu mesocarp powder is a promising pharmaceutical excipient for the development of herbal tablets containing the Lippia origanoides extract.
\end{abstract}

Keywords: Lippia origanoides/pharmaceutical formulation/toxicity/. Babassu mesocarp. Factorial planning. Tablets.

\section{INTRODUCTION}

Lippia origanoides H.B.K. (Verbenaceae) is a honey plant native to Central America and northeastern South America, whose medicinal potential has been widely investigated due to the high amount of bioactive compounds identified, such as the flavanones naringenin and pinocembrin, and the flavones quercetin and luteolin

\footnotetext{
*Correspondence: A. G. Coelho. Laboratório de Geoquímica Orgânica, Universidade Federal do Piauí, Campus Ministro Petrônio Portella, CEP 64049-550, Ininga, Teresina, PI, Brasil. Phone: +55863215 1160. E-mail: angelicacoelho13@gmail.com.
}

(Stashenko et al., 2013; Barreto et al., 2014). Coelho et al. (2015) showed that a standardized hydroalcoholic extract of $L$. origanoides (Lo-HAE), obtained after optimization of extraction conditions, induces a significant hypotensive effect when administered intravenously or orally to rats, with duration of approximately 5 hours after oral administration.

According to World Health Organization (2016), cardiovascular diseases are the main cause of death in the world, and hypertension is the main risk factor for the occurrence of these diseases. Taken together, the development of a pharmaceutical formulation from $L$. origanoides is markedly relevant, prospecting the industrial production of a new therapeutic herbal medicine for the 
treatment of arterial hypertension. Among the alreadyexisting pharmaceutical forms, tablets are suitable choices for the long-term treatments, such as required for arterial hypertension. Tablets promote a systemic drug delivery through the convenient and safe administration of daily doses of the drug, then ensuring greater dose precision and having low cost and ease of production on an industrial scale (Guerra-Ponce et al., 2016; Klein et al., 2013).

However, focusing on the industrial-scale production of herbal medicines, the different drying techniques available are promising alternatives for the conservation and stocking of plant extracts, providing greater stability, preserving their physicochemical characteristics and pharmacological properties. Among these techniques, spray-drying is widely used in the herbal industry. Since the equipment allows the association with appropriate drying excipients (such as colloidal silicon dioxide), as well as the direct feed of liquids with direct discharge of powder, it is a productive and highly versatile method that confers stability and allows the control of the characteristics of the final product, thus ensuring reproducibility of the processes (Fernandes et al., 2014).

The babassu mesocarp (Orbygnia sp.), one of the main extractive products from Brazil, emerged as a raw material with great potential for the development of tablets in the pharmaceutical industry as an excipient, due to its composition of around $70 \%$ of starch. Starches are natural, profitable and non-toxic biopolymers, which is widely used as binders and disintegrants of the formulations (França et al., 2014). The advantages of using babassu mesocarp in pharmaceutical formulations versus the use of conventional excipients have been studied. A comparative statistical study can be performed, such as Factorial Planning, which compares the characteristics of formulations produced from different mixtures of excipients. Using this tool, simultaneous variables are analyzed with a reduced number of experiments, but not causing the lack of data quality (Lima et al., 2016).

The use of plant extracts as bioactive raw materials requires the evaluation of their toxicity. In this sense, procedures which assess the toxicological profile of chemical products classify them according to their toxicological potentials, including lethality. Therefore, it is imperative that the toxicological assessment must be performed following internationally regulated protocols, such as the guidelines published by the Organization for Economic Cooperation and Development (OECD) (Jonsson et al., 2013).

The present work aims to develop pharmaceutical tablet formulations and assess the acute oral toxicological profile for a spray-dried standardized extract of $L$. origanoides H.B.K., evaluating the influence of excipients in the process.

\section{MATERIAL AND METHODS}

\section{Drugs and reagents}

During the analyses, ethanol (purity $>99.5 \%$; Isofar, Petrópolis, RJ, Brazil) and ultra-purified water (Milli Q ${ }^{\circledR}$, Merck Millipore, Darmstadt, Germany) were used. The standard naringenin $\left(\mathrm{C}_{15} \mathrm{H}_{12} \mathrm{O}_{15}, 95.0 \%\right)$ was obtained from Sigma-Aldrich (St. Louis, MO, USA). For the analyses in UFLC, methanol (Labsynth, Diadema, SP, Brazil) and acetic acid (Vetec Química Fina, Rio de Janeiro, RJ, Brazil) both in HPLC grade were used.

The leaves of $L$. origanoides H.B.K. were collected in José de Freitas, Piauí, Brazil (latitude $04^{\circ} 45^{\prime} 23^{\prime}$ " south and longitude $42^{\circ} 34^{\prime} 32^{\prime \prime}$ west), in 2013. The determination of the species was realized at the Herbarium Graziela Barroso from Federal University of Piauí. The voucher specimen was deposited under $n^{\circ}$ TEPB 09205.

\section{Preparation of the spray-dried L. origanoides hydroalcoholic extract (Lo-HAE)}

The hydroalcoholic extract of L. origanoides (LoHAE) was obtained according to the procedure previously optimized and standardized by Coelho et al. (2015). For this purpose, the plant material was dried at room temperature and then milled with a knife mill. Then, $1004 \mathrm{~g}$ of leaves were extracted by maceration with $8 \mathrm{~L}$ of ethanol / water (1: 1) for three days, filtering the extract and renewing the solvent every day. The hydroalcoholic extract (Lo-HAE) was subjected to rotation evaporation and after evaporation of ethanol, part of the material was subjected to drying for lyophilization in Micro Modulyo Edwards Lyophilizer coupled to a high vacuum ValPump VLP80 Savant pump and another part of the extract was intended for spray drying. In this step, Aerosil $200^{\circledR}$ (colloidal silicon dioxide) was added to the aqueous residue as a drying adjuvant at $30 \%$ of the mass of the solid residue of the Lo-HAE, previously determined according to the methodology described in the Brazilian Pharmacopoeia, $5^{\text {th }}$ edition. The Lo-HAE plus colloidal silicon dioxide (Lo-HAE/CSD) was subjected to drying in Mini Spray Dryer (Büch; B-290), using inlet and outlet temperatures of $150{ }^{\circ} \mathrm{C}$ and $100{ }^{\circ} \mathrm{C}$, respectively. The peristaltic pump speed $\left(3 \mathrm{~mL} \cdot \mathrm{min}^{-1}\right)$ was maintained at $10 \%$ of the maximum capacity of the equipment. The pressure was maintained constant (55 bar), and the air suction was adjusted at $80 \%$ of the total capacity. 


\section{Preparation of the tablets by Factorial Planning $2^{3}$}

Using the spray-dried extract (Lo-HAE/CSD), powder mixtures were prepared for 8 (eight) different lots of tablets determined by factorial design $\left(2^{3}\right)$, in which the following parameters were combined at two levels: diluent (microcrystalline cellulose (CMC) or babassu mesocarp powder), percentage of lubricant (magnesium stearate 1.0 or $0.5 \%$ ), and presence or absence of the binder $1.0 \%$ polyvinylpyrrolidone (PVP), as shown in Table I. Microcrystalline cellulose PH 101 (supplier: Genix ${ }^{\circledR}$, Brazil; Lot number: 90652) and magnesium stearate (supplier: Natural Pharma ${ }^{\circledR}$, Brazil) were used. The babassu mesocarp powder was obtained from Ativa Vida Ltda, Brazil (Lot number: 1841003), and submitted to a bleaching process, in order to avoid interference of chromophore groups present in the further applied spectrophotometric analysis (Rosa et al., 2011). The bleaching process was performed using the methodology of Pereira (2010), with modifications.

Table II shows the composition followed for the development of each lot of tablets. All lots were produced by wet method, after previous granulation process in Mesh no. 2, using water-alcohol (1:1) to produce the granules and the dry extract in a spray-dryer at a dose of $50 \mathrm{mg}$. For the groups containing PVP, $1.0 \%$ polyvinylpyrrolidone solubilized in water-alcohol $(1: 1)$ was used in the granulation step. The compression was carried out in a single-punch tablet press (Monopress LM1, Lemaq, SP, Brazil) using a 5-mm punch.

Each lot $(n=40)$ was assessed for macroscopic characteristics, including color, surface roughness, and the presence of physical defects, as well as the average weight (analytical balance, Sartorius model BL 210S), thickness and diameter (caliper, Starret ${ }^{\circledR}$ model 125/6), hardness (digital durometer, Nova Ética ${ }^{\circledR}$ model 298DGP), friability (friabilometer, Nova Ética ${ }^{\circledR}$ model 300 ), and disintegration time (disintegrator, Nova Ética ${ }^{\circledR}$ model $301 \mathrm{AC}$ ), according the methodologies described in the Brazilian Pharmacopoeia V (2010).

\section{Quantification of the marker Naringenin in dried extracts and tablets by UFLC}

As previously reported by Coelho et al. (2015), quantitative analyses of Lo-HAE in the formulations can be performed based on the presence of the marker naringenin. For the quantification of the naringenin content in the spray-dried Lo-HAE/CSD, the sample was initially submitted to a clean-up in C18ec solid-phase extraction cartridge (Chromabond $\AA$ ) using methanol as the eluent, followed by filtration of the eluate on nylon filter $(0.2 \mu \mathrm{m}$, Titan 3$)$. After drying, the methanolic solutions were prepared in triplicate at a concentration of $0.0495 \mathrm{mg} \cdot \mathrm{mL}^{-1}$ for injection in Ultra-Fast Liquid Chromatograph (UFLC) (Shimadzu Prominence), equipped with a DGU-20A3 degasser and pump Binary LC-20AD Shimadzu, coupled to a PDA UV detector (Shimadzu). The analysis conditions followed the methodology developed by Coelho et al. (2015), and the area of the signal relative to naringenin in Lo-HAE/ CSD was calculated. Using the linear equation obtained from the analytical curve fitted for the naringenin from six different concentrations $(1.56,2.08,3.12,3.64,4.16$ and $\left.4.68 \mathrm{mg} \cdot \mathrm{L}^{-1}\right)$, the quantification of the marker content in the solutions were analyzed and quantified.

Regarding the quantification of naringenin in the tablets, only lots no. 2, 4, 6 and 8 which contained the

TABLE I - Factorial planning matrix $2^{3}$ for optimization of Lippia origanoides H. B. K. tablets. Diluent (cellulose-; babassu+); Use of PVP $1 \%$ as a binder (no -, yes + ), Lubricant $(0,5 \%-; 1,0 \%+)$. Interaction of parameters 1 e $2(1 / 2)$; Interaction of parameters 1 e $3(1 / 3)$; Interaction of parameters 2 e $3(2 / 3)$; e Interaction of parameters 1,2 e $3(1 / 2 / 3)$

\begin{tabular}{|c|c|c|c|c|c|c|c|}
\hline Assay & Diluent (1) & $\begin{array}{l}\text { Presence of } \\
\text { Binder (2) }\end{array}$ & Lubricant (3) & $(1 / 2)$ & $(1 / 3)$ & $(2 / 3)$ & $(1 / 2 / 3)$ \\
\hline 1 & - & - & - & + & + & + & - \\
\hline 2 & + & - & - & - & - & + & + \\
\hline 3 & - & + & - & - & + & - & + \\
\hline 4 & + & + & - & + & - & - & - \\
\hline 5 & - & - & + & + & - & - & + \\
\hline 6 & + & - & + & - & + & - & - \\
\hline 7 & - & + & + & - & - & + & - \\
\hline 8 & + & + & + & + & + & + & + \\
\hline
\end{tabular}


TABLE II - Definition of the composition of the different lots of tablets according to the factors under study (diluent, presence of binder and percentage of lubricant)

\begin{tabular}{cccccccc}
\hline Lot Number & Diluent & $\begin{array}{c}\text { Presence of } \\
\text { PVP Binder }\end{array}$ & $\begin{array}{c}\text { Lubricant } \\
(\mathbf{\% )}\end{array}$ & Number of lot & Diluent & $\begin{array}{c}\text { Presence of } \\
\text { PVP Binder }\end{array}$ & $\begin{array}{c}\text { Lubricant } \\
(\%)\end{array}$ \\
\hline Lot 1 & Cellulose & No & 0.5 & Lot 5 & Cellulose & No & 1.0 \\
Lot 2 & Babassu & No & 0.5 & Lot 6 & Babassu & No & 1.0 \\
Lot 3 & Cellulose & Yes & 0.5 & Lot 7 & Cellulose & Yes & 1.0 \\
Lot 4 & Babassu & Yes & 0.5 & Lot 8 & Babassu & Yes & 1.0 \\
\hline
\end{tabular}

babassu mesocarp powder as diluent were analyzed, since they meet the best quality parameters. For this purpose, tablet samples from each lot were analyzed by UFLC, in triplicate, under the same conditions as described above.

\section{In vitro dissolution assay}

The dissolution test was carried out only for lots containing babassu mesocarp powder as diluent, due to the lots containing cellulose did not meet the quality criteria in the disintegration test. A calibration curve for the hydroalcoholic extract of $L$. origanoides was fitted at concentrations of $10.4 ; 15.2 ; 24 ; 32$ and $40 \mu \mathrm{g} \cdot \mathrm{mL}^{-1}$ in 0.1 $\mathrm{M} \mathrm{HCl}$, and read at the wavelength of $290 \mathrm{~nm}$, according to previous scanning. Then, the naringenin content in tablets dissolved using a dissolution test equipment (Nova Ética ${ }^{\circledR}$, model 299, Brazil) were calculated. The parameters of rotation were defined as follow: speed at 50 RPM; temperature at $37^{\circ} \mathrm{C}$; and $900 \mathrm{~mL}$ of $0.1 \mathrm{M} \mathrm{HCl}$ medium per vessel. The samples were collected at 5, 10, 15, 30, 45, 60 and 75 minutes, according to the Brazilian Pharmacopoeia 5 th ed (2010) guideline for dissolution of immediate release tablets. The dissolution curves were plotted using GraphPad Prism version 6.00 for Windows, (GraphPad Software, La Jolla California USA, www.graphpad.com).

\section{In vivo toxicological assessment of spray-dried Lo-HAE}

\section{Animals}

Female Wistar rats (230 $\pm 30 \mathrm{~g}$; 4 months-old) were kept in cages and separated by experimental group. The room temperature was maintained at $24 \pm 2{ }^{\circ} \mathrm{C}$, under light-dark cycle of $12 / 12$ hours. The rats were fasted for $12 \mathrm{~h}$ prior to administration, with the food reintroduced $3 \mathrm{~h}$ after administration. Thereafter, water and food were administered ad libitum. This study was approved by the Animal Experimentation Ethics Committee of the Federal University of Piauí ( $\left.n^{\circ} 008 / 12\right)$. All animals were treated in accordance with the principles defined by the Resolution
No. 1000/2012 of the Federal Council of Veterinary Medicine, Brazil.

\section{Acute oral toxicity test}

The toxicological assessment was carried out in accordance with the Guideline no. 423 from the Organization for Economic Cooperation and Development (OECD) and the Acute Toxicity Class Method. Briefly, rats were initially divided into two groups of three animals each; group 1 were orally treated with Lo-HAE/CSD at the single dose of $2000 \mathrm{mg} / \mathrm{kg}$ (equivalent to $1400 \mathrm{mg} / \mathrm{kg}$ of Lo-HAE and $600 \mathrm{mg} / \mathrm{kg}$ of colloidal silicon dioxide), and group 2 were orally treated with distilled water (vehicle). Thereafter, the hippocratic screening was carried out, where animals were individually observed for clinical and behavioral alterations. After 14 days of daily observation, the animals were euthanized, and gross pathological (macroscopic) analyses of the heart, liver, lung, spleen and kidneys were performed.

\section{Statistical analysis}

The results were analyzed, and significances were determinated by analysis of variance (ANOVA). The statistical analyses and curve fitting were performed using GraphPad Prism version 6.00 for Windows, (GraphPad Software, La Jolla California USA, www.graphpad.com). Pareto and surface charts were constructed, respectively, using the software Excel ${ }^{\circledR}$ version 2013 (Microsoft, www. microsoft.com) and Statistica ${ }^{\circledR}$ version 12 (StatSoft, www. statsoft.com.br).

\section{RESULTS AND DISCUSSION}

\section{Spray-dryed Lo-HAE and characteristics of tablets produced by Factorial Planning $2^{3}$}

The drying of Lo-HAE in a spray-dryer showed a yield of $77.94 \%$. This yield is satisfactory and exceeds the yields normally obtained in laboratory-scale spray-drying, 
which are around 50 to $70 \%$ (Li et al., 2010). Therefore, the spray-drying technique demonstrates efficiency in providing the optimized extract of $L$. origanoides for the production of tablets.

In the macroscopic analysis of the tablets, all the lots presented adequate characteristics, such as circular, flat, free of cracks or deformations (Table III). Besides, the average weight $(100 \mathrm{mg})$ demonstrated satisfactory results according to the Brazilian Pharmacopoeia $5^{\text {th }}$ ed. (2010). For uncoated tablets weighting between $80 \mathrm{mg} 250$ $\mathrm{mg}$, the allowed variation limits must be around $\pm 7.5 \%$. The uniformity of the characteristics of the tablets was maintained when the diameters were analyzed. They all had $5 \mathrm{~mm}$, which demonstrates the quality of the punches, although a significant difference was observed between the thickness of lots containing babassu tablets (lots 2, 4 and 6 ) and two lots containing cellulose and $1.0 \%$ magnesium stearate (Lots 5 and 7).

Two main ways to evaluate the resistance of tablets are the analysis of friability and hardness. Tablets are expected to present some resistance to impacts of the productive process, transportation and storage. Furthermore, physical resistance is a key feature in the development of tablets since administration of the therapeutic dose might be impaired due to the loss of powder and fragments that further compromise the performance of the pharmaceutical form in both disintegration steps and in vivo dissolution of the drug (Nart et al., 2017).

According to Table III, the friability analysis shows that all lots meet the requirement of the Brazilian Pharmacopoeia $5^{\text {th }}$ ed. (2010), where the tolerable friability limit is $1.5 \%$ of weight. For the hardness, which represents the resistance of the tablet to crushing or rupture under radial pressure, lots have also proved to be satisfactory. However, the hardness of the lots produced with babassu mesocarp is significantly lower when compared to lots produced with cellulose. For the study of the influence exerted by each factor on hardness, as well as their interactions, the limit value for significance was calculated with $95 \%$ of confidence (Anova followed by Tukey's post test), and only values above $1.37 \mathrm{~N}$ may be considered significant for the response obtained. Thus, the Pareto Graph was plotted (Figure 1), where it is possible to note that the diluent (babassu or cellulose) promoted the most influenced the increase in hardness, providing a gain of $63 \mathrm{~N}$ when the formulation contains cellulose (encoded as negative value in the Factorial Planning $2^{3}$ matrix). In addition, the presence of the PVP binder also significantly influenced the hardness of the tablets, increasing this parameter by $21 \mathrm{~N}$. The lubricating factor did not present significant influence. Regarding the interaction between the factors, it can be observed that the diluent and binder increase the hardness when this interaction is negative, which can be represented, according to the factorial design matrix 23 , by the occurrence of cellulose as a diluent and the presence of PVP. Similarly, the three factors associated, when a negative interaction is generated, can increase the hardness by $15.25 \mathrm{~N}$. It can be assumed that the presence of cellulose as a diluent is the main factor which is related to the well-known dry binder effect of this excipient (Nart et al., 2017).

Similar to the Pareto Graph, the surface charts of factorial design $2^{3}$ (Figure 2 ) shows the evolution of tablets hardness when the diluent is changed from babassu $(+)$ to cellulose (-) (Figure 2a), and in the presence $(+)$ or absence (-) of the PVP binder (Figure 2b), or the magnesium stearate lubricant (Figure 2c). The significantly higher hardness of

TABLE III - Result of quality control analyzes for developed tablets. ANOVA followed by Tukey post-test: a: significantly higher in relation to the groups whose babassu comprised the formulation $(p<0.01)$; b: significantly less than lots 5 and 7 , ( $<<0.05)$. D.T: Disintegration time; Content: content of marker naringenin

\begin{tabular}{cccccccc}
\hline Lot number & $\begin{array}{c}\text { Average } \\
\text { weight }(\mathbf{g})\end{array}$ & $\begin{array}{c}\text { Thickness } \\
(\mathbf{m m})\end{array}$ & $\begin{array}{c}\text { Diameter } \\
(\mathbf{m m})\end{array}$ & Friability (\%) & Hardness (N) & D.T (min) & Content (\%) \\
\hline 1 & $100.7 \pm 1.59$ & $4.9 \pm 0.06$ & 5 & 0.44 & $95.88 \pm 1.75^{\mathrm{a}}$ & 49 & \\
2 & $99.97 \pm 1.4$ & $4.8 \pm 0.00^{\mathrm{b}}$ & 5 & 0.8 & $35.13 \pm 1.50$ & 25 & 92.76 \\
3 & $100.58 \pm 1.25$ & $4.9 \pm 0.00$ & 5 & 0.52 & $99 \pm 0.71^{\mathrm{a}}$ & 48 & \\
4 & $100.43 \pm 1.05$ & $4.8 \pm 0.00^{\mathrm{b}}$ & 5 & 0.16 & $36.75 \pm 2.60$ & 27 & 84.72 \\
5 & $101.82 \pm 1.41$ & $5 \pm 0.1$ & 5 & 0.53 & $61.5 \pm 1.47^{\mathrm{a}}$ & 44 & 100.27 \\
6 & $100.05 \pm 1.14$ & $4.8 \pm 0.00^{\mathrm{b}}$ & 5 & 0.29 & $30.63 \pm 2.02$ & 17 & \\
7 & $101.66 \pm 0.88$ & $5 \pm 0.00$ & 5 & 0.64 & $124.25 \pm 1.76^{\mathrm{a}}$ & 47 & \\
8 & $100.92 \pm 1.42$ & $4.9 \pm 0.12$ & 5 & 0.38 & $39.37 \pm 1.6$ & 17 & 90.08 \\
\hline
\end{tabular}




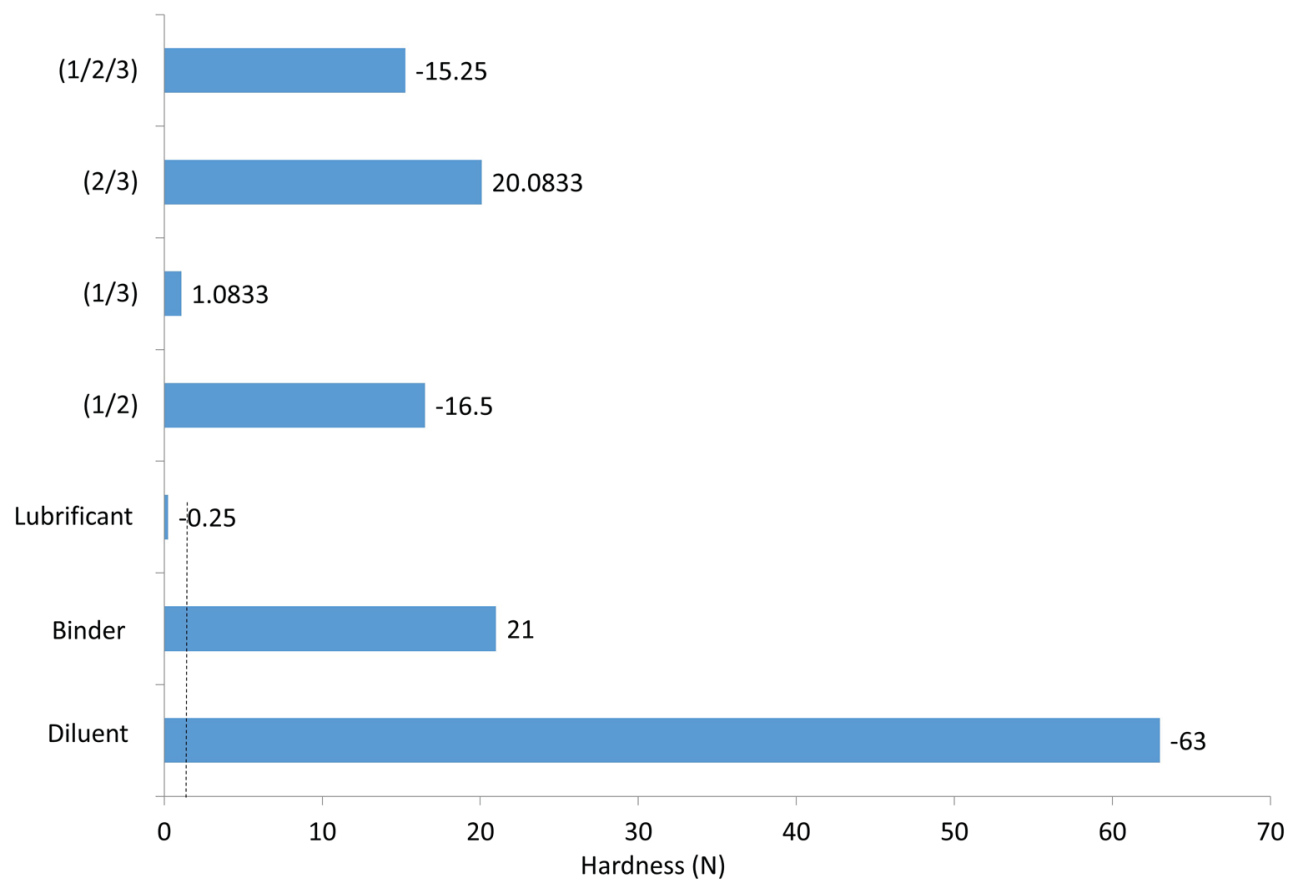

FIGURE 1 - Pareto Graph for factorial planning $2^{3}$ results, considering the effects produced in the hardness. Dashed line defines $95 \%$ confidence interval. Interaction of parameters 1 and $2(1 / 2)$; Interaction of parameters 1 and 3(1/3); Interaction of parameters 2 and $3(2 / 3)$; and Interaction of parameters 1,2 and $3(1 / 2 / 3)$.

the cellulose containing tablets directly influences upon the disintegration time. However, although the direct ratio of hardness to tablet disintegration time is consistent with its mechanical resistance standard, it cannot be established as a rule, since the mechanical resistance of tablets is also determined by the compression technique employed, the density and the flow properties of the powders (active and excipients) (Ferreira et al., 2013).
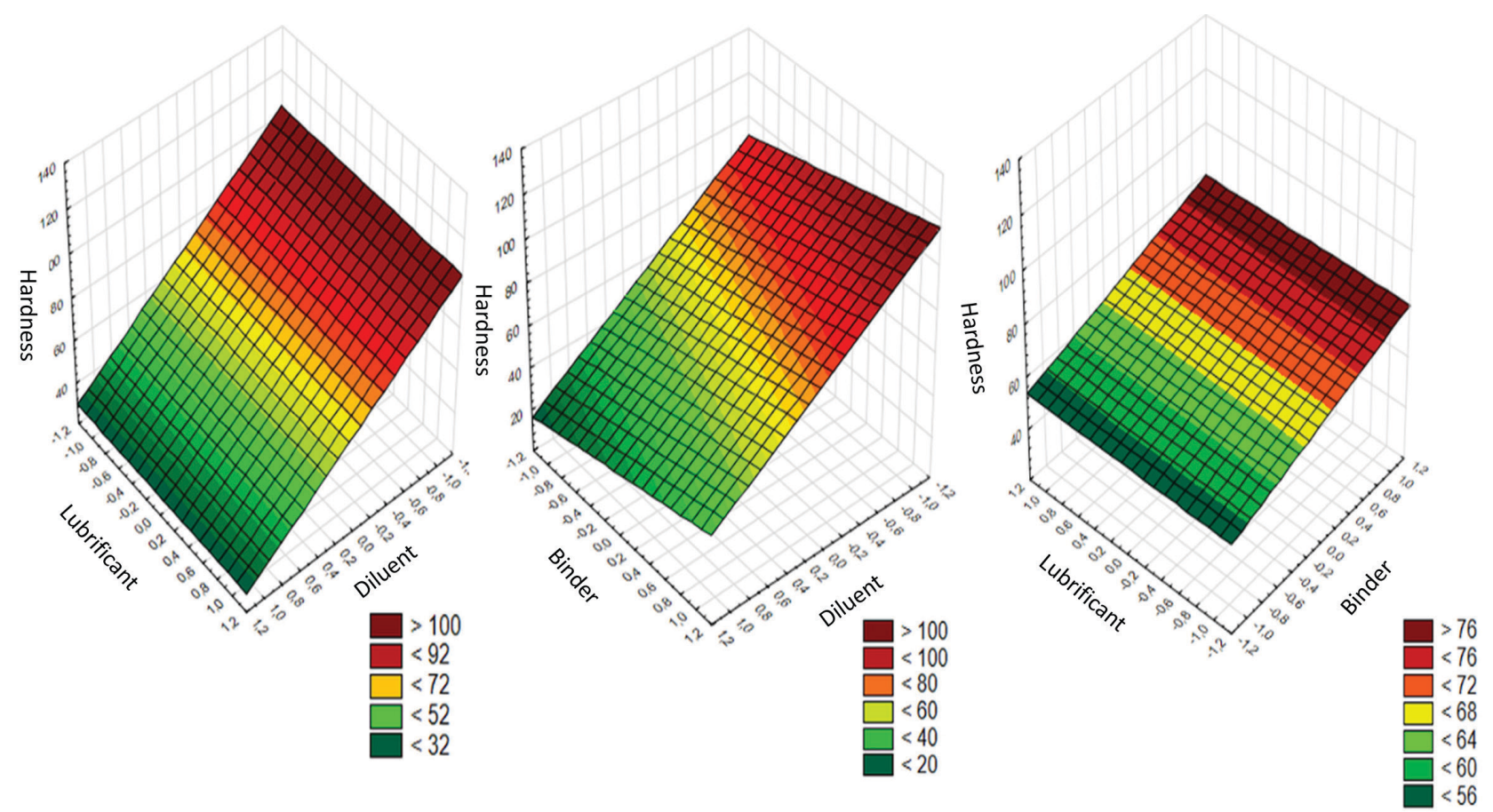

FIGURE 2 - Surface graphics of factorial planning $2^{3}$ for effects produced in hardness (N), from the factors: diluent (cellulose -, babassu +$)$; Use of PVP as a binder (no -, yes +$)$, lubricant $(0.5 \%-; 1.0 \%+)$. 
As followed for the hardness test, the significance was considered with $95 \%$ of confidence for the disintegration time, and only values above 2.49 min could be considered as significant. According with Pareto Graph (Figure 3), it can be seen that the diluent factor was the one that most influenced the increase in the disintegration time, yielding a gain of $25.33 \mathrm{~min}$ when the formulation contains cellulose. On the other hand, the presence of the PVP binder did not significantly have any influence, whereas the lubricant in the $0.5 \%$ concentration increased in $5.83 \mathrm{~min}$ the disintegration time. Considering the interaction between the factors, it can be seen that only the association between diluent and lubricant (which increases the disintegration time when this interaction is negative) can be represented, according to the factorial planning matrix $2^{3}$, by the occurrence of cellulose as diluent and the presence of $1.0 \%$ magnesium stearate, or even by the occurrence of babassu as a diluent and $0.5 \%$ lubricant.

According to the surface chart of effects produced at the disintegration time, the direct relationship with the hardness of the tablets is related to the type of diluent used can be noted, with longer disintegration times when the diluent cellulose (-) was used instead of babassu $(+)$ (Figure 4a). Besides, longer disintegration times $(>35$ min) have been related to the presence of lubricant at the concentration of $0.5 \%(-)$, when compared with the concentration of $1.0 \%(+)$, where times less than $31 \mathrm{~min}$ was obtained (Figure 4c). However, this result contrasts with the expected, since the higher concentration of the lubricant could be related to a longer disintegration time of the formulation. Considering the hydrophobic nature of magnesium stearate, there is a predisposition to cover particles, and making difficult penetration of water into the tablet, and then could promote a delay in the disintegration time (Li, Wu, 2014; Soares, Petrovick, 1999). On the other hand, the effect of lubricants on the tablets depends not only on their physicochemical nature, but also on the presence of active substances and other excipients which may influence the role of the lubricant in increase the disintegration time of the formulation, such as the disintegrating agents (Wang, Wen, Desai, 2010). In the study by Bolhuis et al. (1982), the presence in tablets of the disintegrant $4.0 \%$ sodium starch glycolate renders the disintegration time independent of the presence of magnesium stearate. In these sense, the lower disintegration times observed for the presence of the $1.0 \%$ magnesium stearate may be possibly related to the presence of babassu mesocarp powder might. In accordance with stated above, its potential use in tablet development as a function of the demonstrated disintegrating ability is closely related to the high starch content of this extractive product.

Besides, it was also suggested that the disintegration time is increased at the $0.5 \%$ concentration of lubricant due to the influence of the PVP binder. PVP has the potential to make the granules more cohesive, and then impairing the disintegration of the formulations (Figure 4c) (Late, Yu, Banga, 2009). However, as shown in the Pareto graph (Figure 3), the presence of binder in the formulation did not result in a statistically significant influence.

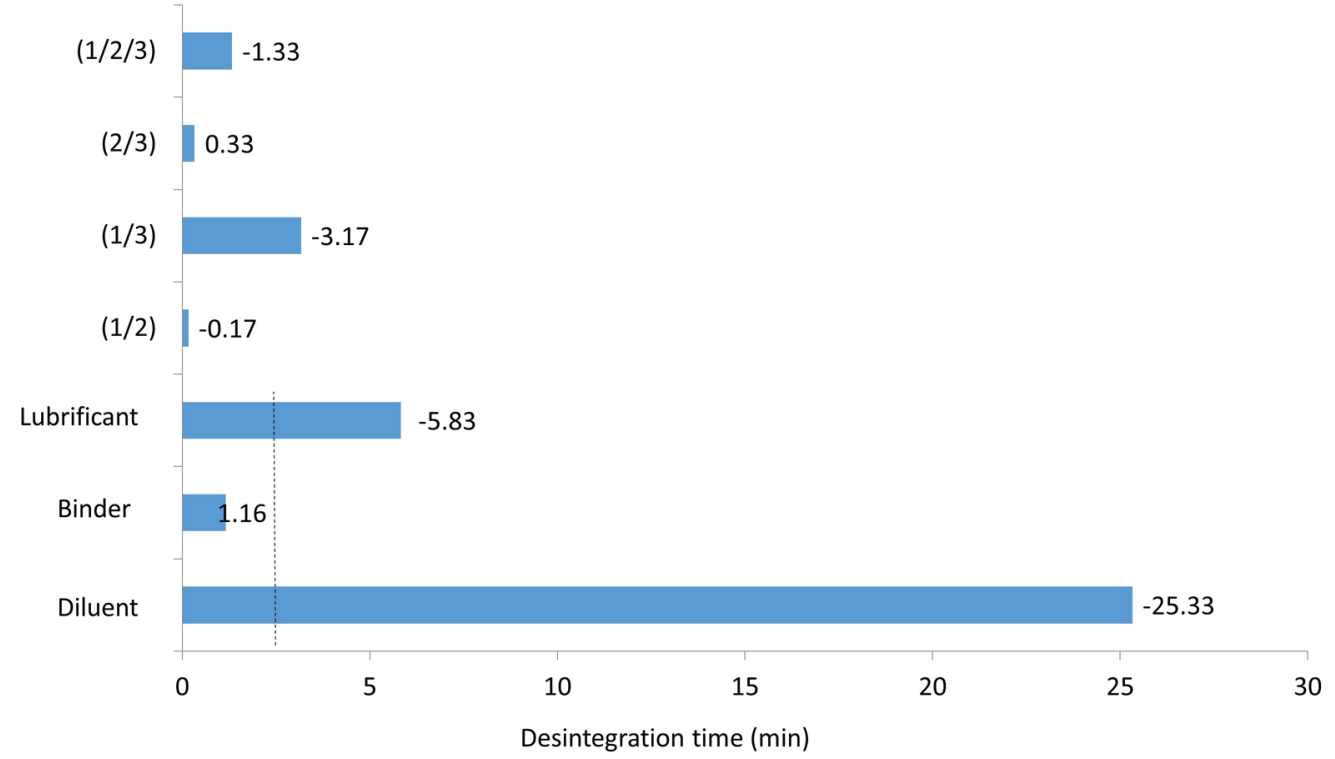

FIGURE 3 - Pareto Graph for factorial planning $2^{3}$ results, considering the effects produced in the disintegration time. Dashed line defines $95 \%$ confidence interval. Interaction of parameters 1 and $2(1 / 2)$; Interaction of parameters 1 and 3(1/3); Interaction of parameters 2 and $3(2 / 3)$; and Interaction of parameters 1,2 and $3(1 / 2 / 3)$. 

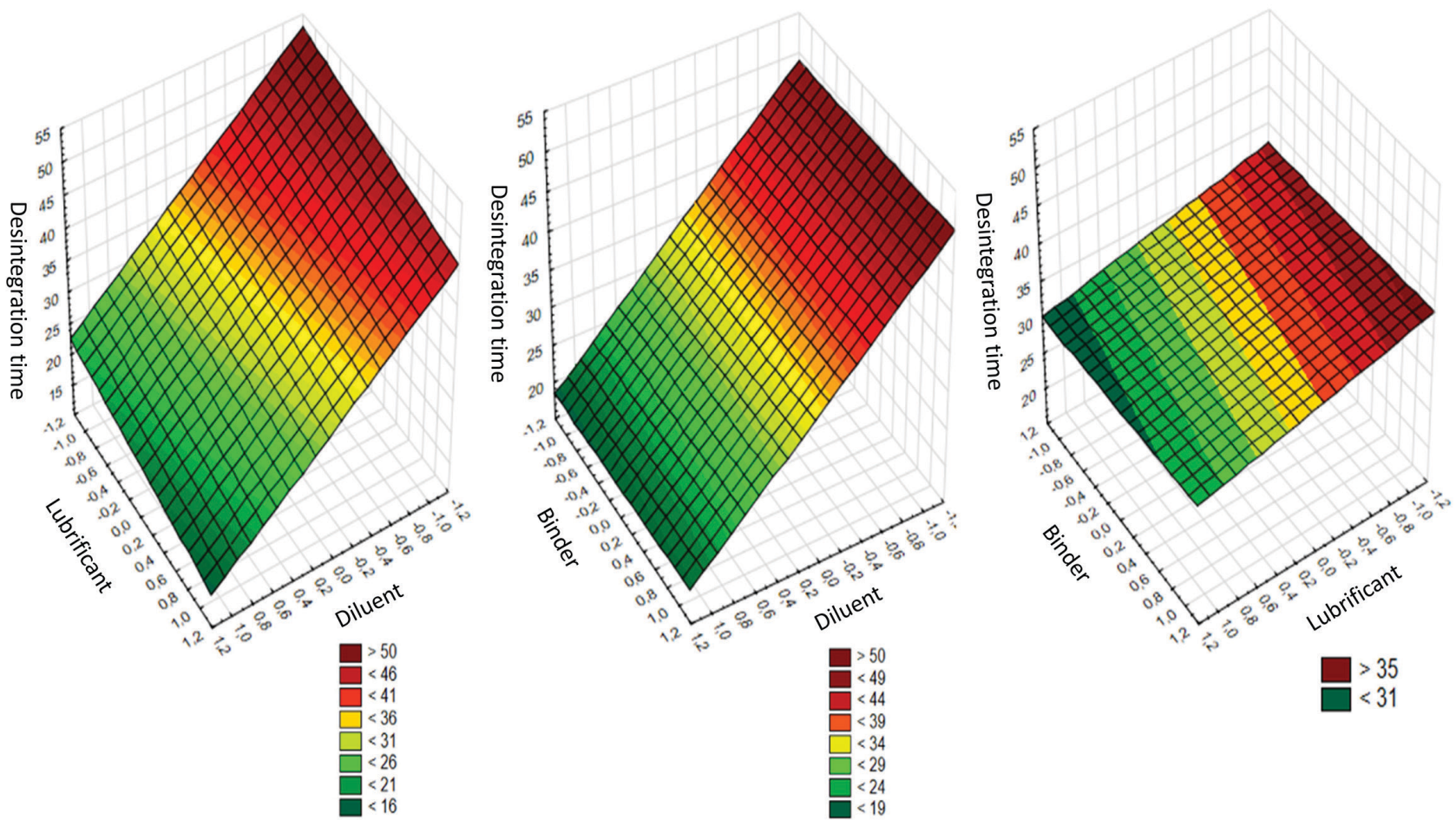

FIGURE 4 - Surface graphics of factorial planning $2^{3}$ for effects produced in disintegration time (min), from the factors: diluent (cellulose -, babassu +); use of PVP as a binder (no -, yes +), lubricant $(0.5 \%-; 1.0 \%+$ ).

Thus, according the criteria established in the Brazilian Pharmacopoeia $5^{\text {th }}$ ed. (2010), the maximum disintegration time accepted for immediate-release tablets is 30 minutes. Therefore, only the tablets containing babassu meet a satisfactory disintegration time of less than 30 minutes, whereas the tablets containing cellulose as diluent were not approved in this test (Table III; Figure 3).

\section{Determination of the naringenin marker on Lo- $\mathrm{HAE} / \mathrm{CSD}$ and tablets}

For the quantification of naringenin in the spraydried extract, the signal area relative to the marker present in the chromatogram was analyzed. The data of signal area were plotted on the line equation $(y=42313.5809 x-$ 11226.3496) previously obtained from the analytical curve of the marker naringenin $(\mathrm{R}=0.9993)$. The concentration of naringenin detected in the spray-dried extract was 3.73 $\mathrm{g} \%$. Such result is satisfactory, since the same content of the marker was detected in the lyophilized extract of $L$. origanoides (37.3 mg of Naringenin per gram of Lo-HAE, or $3.73 \mathrm{~g} \%$ ), as presented by Coelho et al. (2015). Thus, the application of spray-drying technique as well as the presence of Aerosil ${ }^{\circledR}$ as a drying adjuvant did not influence the naringenin content in the Lo-HAE, making safe the use of this technique for the production of dry extracts for pharmaceutical application as raw materials in the industrial production of tablets.

Furthermore, the quantification of naringenin content in the tablets using the linear equation obtained for this marker was also performed, as well as the Lo-HAE content present in the formulations (Table III). The results showed that formulation 6 (Babassu as diluent, without PVP and $1.0 \%$ of lubricant) provided the best result, since it presented a naringenin content of $100.27 \%$, thus ensuring the Lo-HAE content of $50 \mathrm{mg}$ in this lot, which is required in the preparation of the formulations. Thus, the formulation present in lot 6 is more suitable according the proposed analytical method.

\section{Dissolution test}

The tablet dissolution step is markedly decisive for delivery of drugs towards the site of action. After dissolution, the drug is released from this pharmaceutical form, and becomes available to be absorbed. Many factors can interfere in the process of tablet dissolution, such as the particle size, solubility, and chemical nature of the drug, as well as the composition in excipients of the formulation (Arrunátegui et al., 2015; Cristofoletti, Dressman, 2017). 
The FDA (Food and Drug Administration, USA) states that these formulations must release $85 \%$ of the active substance between the initial 15 and 60 minutes of the test, according to the biopharmaceutical characteristics of the drug (FDA-CDER, 1997). In this work, only lots containing PVP meet this specification, since almost all Lo-HAE present in the tablets were released within 60 minutes of assay. Furthermore, the better dissolution profiles were obtained for the lots containing magnesium stearate at the lowest concentration $(0.5 \%)$ (Figure 5$)$. This fact is justified by the characteristic insolubility of the lubricants which delay the dissolution process. On the other hand, the starch as the major constituent of the babassu mesocarp powder facilitates the dissolution process, since this excipient also acts as a disintegrant in the formulations. In addition, spray-drying process is able to reduce the size of the dried extract particles, and thus improve their dissolution. Finally, the dissolution profile obtained for the tablets can also be related to the wet granulation process performed, which generally confers more hydrophilic characteristics to the poorly soluble constituents (Li, Wu, 2014).

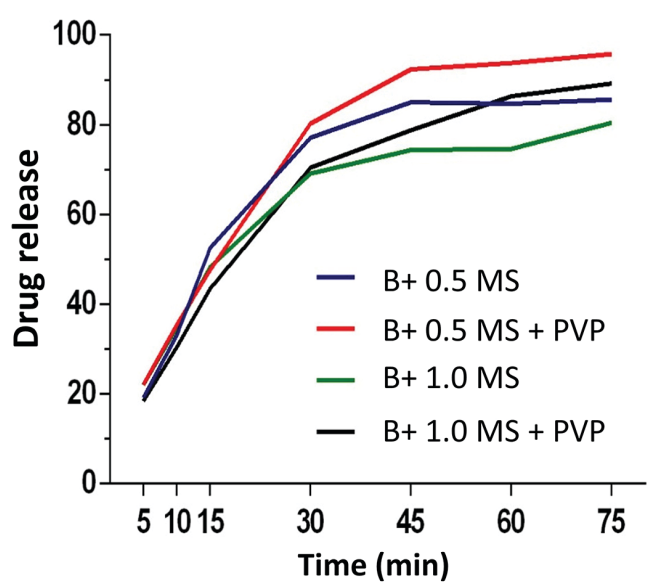

FIGURE 5 - Dissolution profile of lots containing babassu as diluent (B). B + 0.5 MS: Magnesium Stearate 0.5\%; B + 0.5 MS + PVP: Magnesium Stearate $0.5 \%$ and PVP as a binder; $\mathrm{B}+1.0$ MS: Magnesium Stearate 1\%; B + 1.0 MS + PVP: Magnesium stearate $1.0 \%$ and PVP as a binder.

As mentioned above, it is widely accepted that the use of babassu mesocarp powder is able to improve the production of tablets due to its physicochemical characteristics favorable to the release of active compounds. These characteristics can be valuable in order to allow the bioactive compounds present in the optimized extract of $L$. origanoides to be released in order to exert the hypotensive activity previously reported by Coelho et al. (2015). In addition, the quantification of marker compounds in developed formulations represents a marked aspect in the production of herbal medicines in industrial scale. The control quality is performed as the content of plant active compounds, which ensures the reproducibility of the production process, as well as the efficacy and safety of the herbal medicine for potential consumers.

\section{Acute toxicity test of Lo-HAE/CSD}

According to OECD Guideline no. 423, a sample is considered to be practically non-toxic when it presents a value $\mathrm{LD}_{50}$ above $2,000 \mathrm{mg} / \mathrm{kg}$ or between 2,000 and $5,000 \mathrm{mg} / \mathrm{kg}$ (OECD, 2002). The colloidal silicon dioxide is widely used in oral and topical pharmaceutical formulations, being considered as an essentially non-toxic and non-irritating excipient, since only intraperitoneal and subcutaneous administration can produce reactions to local tissues and/or granulomas. The $\mathrm{LD}_{50}$ values in rats for this excipient are $0.015 \mathrm{~g} / \mathrm{kg}$ by intravenous route (IV), and $3.16 \mathrm{~g} / \mathrm{kg}$ for oral route (VO) (Rowe, Sheskey, Quinn, 2009). In the present study, no death was observed during the study period after single oral administration of Lo-HAE $/ \mathrm{CSD}$ at the dose of $2,000 \mathrm{mg} / \mathrm{kg}$. Thus, it can be inferred that the presence of colloidal silicon dioxide as a drying adjuvant at the equivalent dose of $600 \mathrm{mg} / \mathrm{kg}$ in Lo-HAE/CSD did not cause any death. Thus, Lo-HAE/ CSD can be classified in category X of GHS (Globally Harmonized System), which refers to substances where neither death nor toxicological effects were observed.

According to Cunha et al. (2009), the hippocratic screening is a useful trial in the preliminary screening of plants for the detection of possible pharmacological and toxicological activities. It provides a general estimate of the toxicity of a substance, regarding the activity and coordination of the motor system, as well as the reflexes and activities on the central and autonomic nervous system of the tested species. Regarding the hippocratic screening performed, after the administration of Lo-HAE/CSD at the single dose of $2,000 \mathrm{mg} / \mathrm{kg}$, no alterations in clinical or behavior parameters of the treated group was observed. The same result of hippocratic screening was reported by Coelho et al. (2015), after administration of Lo-HAE at dose of $2,000 \mathrm{mg} / \mathrm{kg}$. In addition, in the acute toxicity test conducted by Coelho et al. (2015), no weight loss was observed after administration of the $2,000 \mathrm{mg} / \mathrm{kg}$ dose of Lo-HAE, reinforcing the safe use of this extract. Thus, the Lo-HAE and colloidal silicon dioxide in Lo-HAE/CSD at equivalent doses of 1,400 and $600 \mathrm{mg} / \mathrm{kg}$, respectively, did not affect the analyzed toxicological parameters

After euthanasia of the animals, the organs of the abdominal and thoracic cavities (liver, kidneys, heart, 
spleen and lungs) were macroscopically evaluated. No changes were detected in the size, stiffness, structure or coloring of the surfaces, when compared to the control group. The OECD and the Society of Toxicological Pathology (STP) considers as non recommended the analysis of both relative organ weights and histopathological studies in acute toxicity tests, since a single exposure to the test substance may not be conclusive about toxicological assessment. According to the STP, the determination of relative organ weights and histopathological analysis should be performed after treatment for at least 7 days, unless visible macroscopic changes could be observed (OECD, 2002; Sellers, 2007).

\section{CONCLUSION}

The tablets containing the babassu mesocarp powder demonstrated more significant physicochemical characteristics when compared to the tablets containing cellulose as diluent. It is possible to associate the presence of this excipient with the improvement of hardness and disintegration time of tablets. Therefore, the use of babassu mesocarp powder in the development of a pharmaceutical formulation based on L. origanoides is advantageous. Besides, the determination of naringenin content in the developed formulations was also possible, which represents an imperative criterion for the development of pharmaceutical formulations containing plant extracts. In addition, according to the acute oral toxicity test by Acute Toxic Class Method (OECD), Lo-HAE/CSD showed no signs of toxicity, reinforcing future expectations for the development of herbal formulations.

\section{REFERENCES}

Arrunátegui LB, Silva-Barcellos NM, Bellavinha KR, Ev LS, Souza J. Biopharmaceutics classification system: importance and inclusion in biowaiver guidance. Braz J Pharm Sci. 2015;51(1):143-154.

Barreto HM, Fontinele FC, Oliveira AP, Arcanjo ADR, Santos $\mathrm{BHC}, \mathrm{Abreu} \mathrm{A}$, et al. Phytochemical prospection and modulation of antibiotic activity in vitro by Lippia origanoides H.B.K. in Methicillin resistant Staphylococcus aureus. Biomed Res Int. 2014;2014:305610.

Bolhuis G, Van Kamp H, Lerk C, Sessink F. On the mechanism of action of modern disintegrants. Acta Pharm Technol. 1982;28:111-114.
Brasil. Agência Nacional de Vigilância Sanitária. Resolução da Diretoria Colegiada No ${ }^{\circ} .49$, de 23 de novembro de 2010. Aprova a Farmacopeia Brasileira, $5^{a}$ edição e dá outras providências. Brasília. Diário Oficial da União $\mathrm{N}^{\circ} 224$ de 24 de novembro de 2010.

Coelho AG, Lima Neto JS, Moura AKS, Sousa TO, Morais ICPS, Carvalho GD, Cunha FVM, et al. Optimization and standardization of extraction method from Lippia origanoides H.B.K.: Focus on potential anti-hypertensive applications. Ind Crops Prod. 2015;78:124-130.

Cristofoletti R, Dressman JB. Dissolution methods to increasing discriminatory power of in vitro dissolution testing for ibuprofen free acid and its salts. J Pharm Sci. 2017;106(1):92-99.

Cunha LC, Azeredo FS, Mendonça ACV, Vieira MS, Pucci LL, Valadares MC. Avaliação da toxicidade aguda e subaguda, em ratos, do extrato etanólico das folhas e do látex de Synadenium umbellatum Pax. Rev Bras Farmacogn. 2009;19(2a):403-411.

FDA-CDER. Guidance for Industry. Dissolution testing of immediate release solid oral dosage forms. Rockville: Food and Drug Administration, 1997b. p. 17.

Fernandes MRV, Azzolini AECS, Martinez MLL, Souza CRF, Lucisano-Valim YM, Oliveira WP. Assessment of antioxidant activity of spray dried extracts of Psidium guajava Leaves by DPPH and Chemiluminescence Inhibition in Human Neutrophils. Biomed Res Int. 2014;2014:382891.

Ferreira TF, Mourão ASR, Ribeiro LAL, Freitas MB. Estudo comparativo da influência dos excipientes na qualidade de hidroclorotiazida $25 \mathrm{mg}$ em medicamentos referência e genéricos. Rev Ciênc Farm Básica. 2013;34(1):63-68.

França RC, Chagas-Junior AF, Carvalho EEN, Guimarães LGL, Erasmo EAL, Oliveira LA. Babassu coconut mesocarp (Orbignya sp.) as carbon source for production of culture media for Trichoderma. J Biotec Biodivers. 2014;5(1):88-94.

Guerra-Ponce WL, Gracia-Vásquez SL, González-Barranco P, Camacho-Mora IA, Gracia-Vásquez YA, Orozco-Beltrán E, Felto LA. In vitro evaluation of sustained released matrix tablets containing ibuprofen: a model poorly water-soluble drug. Braz J Pharm Sci 2016;52(4):751-759.

Jonsson M, Jestoi M, Nathanail AV, Kokkonen U, Anttila M, Koivisto P, et al. Application of OECD Guideline 423 in assessing the acute oral toxicity of moniliformin. Food Chem Toxicol. 2013;53:27-32. 
Pharmaceutical development of tablets containing a spray-dried optimized extract from Lippia origanoides H. B. K.

Klein T, Longhini R, Bruschi ML, Mello JCP. Development of tablets containing semipurifi ed extract of guaraná (Paullinia cupana). Braz J Pharmacog. 2013;23(1):186-193.

Late SG, Yu Y, Banga AK. Effects of disintegration-promoting agent, lubricants and moisture treatment on optimized fast disintegrating tablets. Int J Pharm. 2009;365(1-2):4-11.

Li X, Anton N, Arpagaus C, Belleteix F, Vandamme TF. Nanoparticles by spray drying using innovative new technology: The Büchi Nano Spray Dryer B-90. J Control Release. 2010;147(2):304-310.

Li J, Wu Y. Lubricants in pharmaceutical solid dosage forms. Lubricants. 2014;2(1):21-43.

Lima HRS, Sá LLF, Sousa FDL, Nunes LCC. Development of a practical tool for analysis of data obtained by factorial design $2^{2}$ e $2^{3}$ using the software microsoft office excel ${ }^{\circledR} 2007$ (Microsoft Corporation, EUA). Bol Inf Geum. 2016;7(2):39-47.

Nart V, Beringhs AO, França MT, Espíndola B, Pezzini BR, Stulzer HK. Carnauba wax as a promising excipient in melt granulation targeting the preparation of mini-tablets for sustained release of highly soluble drugs. Mater Sci Eng C Mater Biol Appl. 2017;70(1):250-257.

Organisation for Economic Co-operation and Development. OECD. Test $\mathrm{N}^{\circ}$. 423: acute oral toxicity-acute toxic class method. In: OECD Guidelines for the Testing of Chemicals, Section 4. Paris: OECD Publishing; 2002.

Pereira ALS. Extração de nanocelulose de fibras vegetais. Monografia (Curso de Graduação em Engenharia Química). Fortaleza: Universidade Federal do Ceará, UFC; 2010.
Rosa MSL, Silva Filho EC, Nunes LCC, Cruz ETL, Araújo KA. Caracterização do mesocarpo de babaçu (Orbignya $s p$.): termogravimetria e avaliação do conteúdo de amido. In: Congresso Brasileiro de Química, 51, São Luís, 2011. Available from: http://www.abq.org.br/cbq/2011/ trabalhos/12/12-732-11358.htm

Rowe RC, Sheskey PJ, Quinn ME. Handbook of pharmaceutical excipients. 6th ed. Washington: Pharmaceutical Press; 2009.

Sellers RS, Morton D, Michael B, Roome N, Johnson JK, Yano BL, Perry R, Schafer K. Society of Toxicologic Pathology Position Paper: OrganWeight Recommendations for Toxicology Studies. Toxicol Pathol. 2007;35(5):751-755.

Soares LAL, Petrovick PR. Física da compressão. Cad Farm. 1999;15(2):65-79.

Stashenko EE, Martínez JR, Cala MP, Durán DC, Caballero D. Chromatographic and mass spectrometric characterization of essential oils and extracts from Lippia (Verbenaceae) aromatic plants. J Sep Sci. 2013;36(1):192-202.

Wang J, Wen H, Desai D. Lubrication in tablet formulations. Eur J Pharm Biopharm. 2010;75(1):1-15.

World Health Organization. WHO. World health statistics 2016: monitoring health for the SDGs, sustainable development goals. Geneva; 2016.

Received for publication on $18^{\text {th }}$ April 2017 Accepted for publication on $28^{\text {th }}$ November 2017 